\title{
Opening up new horizons for psychiatric genetics in the Russian Federation: moving toward a national consortium
}

\author{
Olga Yu. Fedorenko ${ }^{1,2}$ - Vera E. Golimbet ${ }^{3}$ - Svetlana A. Ivanova ${ }^{1,2}$ - Anastasia Levchenko ${ }^{4} \cdot$ Raul R. Gainetdinov ${ }^{4}$. \\ Arkady V. Semke ${ }^{1}$. German G. Simutkin ${ }^{1}$ • Anna E. Gareeva ${ }^{5,6}$. Andrey S. Glotov ${ }^{7}$ Anna Gryaznova ${ }^{8}$. \\ Ivan Y. lourov ${ }^{3}$ - Evgeny M. Krupitsky ${ }^{9}$ Igor N. Lebedev ${ }^{10}{ }^{10}$. Galina E. Mazo ${ }^{9}$. Vasily G. Kaleda ${ }^{3}$. \\ Lilia I. Abramova ${ }^{3}$ - Igor V. Oleichik ${ }^{3}$ - Yulia A. Nasykhova ${ }^{7}$ - Regina F. Nasyrova ${ }^{9}$ Anton E. Nikolishin ${ }^{11}$. \\ Evgeny D. Kasyanov $\mathbb{D}^{9} \cdot$ Grigory V. Rukavishnikov $\mathbb{D}^{9} \cdot$. Ilgiz F. Timerbulatov ${ }^{6}$. Vadim M. Brodyansky ${ }^{11}$. \\ Svetlana G. Vorsanova ${ }^{12}$. Yury B. Yurov ${ }^{3}$. Tatyana V. Zhilyaeva ${ }^{13}$. Anzhelika V. Sergeeva ${ }^{13}$. Elena A. Blokhina ${ }^{14}$. \\ Edwin E. Zvartau $\mathbb{1}^{14} \cdot$ Anna S. Blagonravova ${ }^{13} \cdot$ Lyubomir I. Aftanas $^{15} \cdot$ Nikolay A. Bokhan $^{1,16} \cdot$ Zurab I. Kekelidze $^{11}$. \\ Tatyana V. Klimenko ${ }^{11}$ • Irina P. Anokhina ${ }^{11}$ • Elza K. Khusnutdinova ${ }^{5,6}$ • Tatyana P. Klyushnik ${ }^{3}$. \\ Nikolay G. Neznanov ${ }^{9}$ - Vadim A. Stepanov ${ }^{10,16}$. Thomas G. Schulze ${ }^{8} \cdot$ Aleksandr O. Kibitov $^{11}$
}

Received: 11 August 2018 / Revised: 27 December 2018 / Accepted: 31 December 2018 / Published online: 21 January 2019

(c) The Author(s) 2019. This article is published with open access

\begin{abstract}
We provide an overview of the recent achievements in psychiatric genetics research in the Russian Federation and present genotype-phenotype, population, epigenetic, cytogenetic, functional, ENIGMA, and pharmacogenetic studies, with an emphasis on genome-wide association studies. The genetic backgrounds of mental illnesses in the polyethnic and multicultural population of the Russian Federation are still understudied. Furthermore, genetic, genomic, and pharmacogenetic data from the Russian Federation are not adequately represented in the international scientific literature, are currently not available for meta-analyses and have never been compared with data from other populations. Most of these problems cannot be solved by individual centers working in isolation but warrant a truly collaborative effort that brings together all the major psychiatric genetic research centers in the Russian Federation in a national consortium. For this reason, we have established the Russian National Consortium for Psychiatric Genetics (RNCPG) with the aim to strengthen the power and rigor of psychiatric genetics research in the Russian Federation and enhance the international compatibility of this research.

The consortium is set up as an open organization that will facilitate collaborations on complex biomedical research projects in human mental health in the Russian Federation and abroad. These projects will include genotyping, sequencing, transcriptome and epigenome analysis, metabolomics, and a wide array of other state-of-the-art analyses. Here, we discuss the challenges we face and the approaches we will take to unlock the huge potential that the Russian Federation holds for the worldwide psychiatric genetics community.
\end{abstract}

These authors contributed equally: Thomas G. Schulze, Aleksandr O. Kibitov

\section{Olga Yu. Fedorenko \\ f_o_y@mail.ru}

Extended author information available on the last page of the article

\section{Introduction}

About 15 years ago, the Russian geneticist E. Rogaev published a paper on academic psychiatry in Russia [1]. However, this interesting report did not provide sufficient details on the direction of major psychiatric genetics research projects being performed at the leading psychiatric centers in Russia.

The problems of genetic research in psychiatry are well known, i.e., the weak effects of multiple genes with an additive and interactive effect; the ambiguity of hypotheses about pathogenesis; psychiatric and somatic comorbidity; 
the lack of reliable and verified laboratory tests; ethnic stratification; and blurred and overlapping diagnostic categories. Some of these problems are particularly relevant to research in the Russian Federation. The population of the Russian Federation, about 144 million people, is very unevenly distributed over a large area and is polyethnic (it includes more than 160 ethnic groups of East and North European and North and Central Asian descent). The predominant ethnic group is Russian $(\sim 81 \%)$. All people in the Russian Federation belong to one of nine language families: Indo-European, Kartvelian, Ural-Yukagir, Altaic, EskimoAleutian, North Caucasian, Yenisei, Sino-Tibetan, and Chukchi-Kamchatka. As a result of significant migration and active interethnic mixing, the population is a complex ethnic conglomerate.

The genetic backgrounds of mental illnesses in the polyethnic and multicultural population of the Russian Federation are still understudied. Genetic, genomic, and pharmacogenetic data from the Russian Federation are not adequately represented in the international scientific literature and thus are not available for meta-analyses and have never been compared with data from other populations.

Most of these problems cannot be solved by individual centers working in isolation but warrant a truly collaborative effort that brings together all the psychiatric genetic research centers in the Russian Federation in a national consortium. Such a consortium will strengthen the power and rigor of psychiatric genetics research in the Russian Federation and enhance the international compatibility of this research.

This paper provides an update on the progress of psychiatric genetics research at centers in the Russian Federation and the international collaborations of these centers and describes the framework and goals of the recently founded Russian National Consortium for Psychiatric Genetics (RNCPG).

\section{The modern landscape of psychiatric genetics in the Russian Federation}

Currently, there are eight psychiatric genetic research centers in five cities in the Russian Federation: the Mental Health Research Center (MHRC) and the Serbsky National Medical Research Center on Psychiatry and Addictions (SNMRCPA) in Moscow; the Mental Health Research Institute (MHRI) and the Research Institute of Medical Genetics (RIMG), Tomsk National Research Medical Center in Tomsk; V.M. Bekhterev National Medical Research Center for Psychiatry and Neurology (BNMRCPN) and the Institute of Translational Biomedicine (ITBM), Saint Petersburg State University (SPBU) in St. Petersburg; the Institute of Biochemistry and Genetics
(IBG), Ufa Scientific Center in Ufa; and Privolzhskiy Research Medical University in Nizhny Novgorod (PRMU). ${ }^{1}$ Below, we present some of the past and current research in psychiatric genetics at these centers.

The Clinical Genetics Laboratory (MHRC, Moscow) has been working in the field of psychiatric genetics and psychiatric genomics for the last three decades. The main focus of its research is molecular genetic studies of schizophrenia (SZ) and affective disorders. Several thousands of clinically well-characterized DNA samples have been collected and used in different kinds of studies, i.e., case-control and family-based association studies and studies of endophenotypes and gene-environment interactions.

Researchers at the MHRC collaborate with other centers for psychiatric genetics worldwide, including the Psychiatric Genomics Consortium (PGC). In addition to 4500 patients from 11 European locations, the first large GWAS in SZ included 500 patients from the Russian population [2]. Later, samples from Russian patients with SZ and bipolar disorder (BD) were used in several collaborative projects, including some with the PGC. The results of these studies contributed to a better understanding of and provided new insights into the genetic architecture of these disorders [3-6]. Also, in 2013 the IBG (Ufa) collaborated with the PGC to perform a GWAS of individuals with SZ who were of Russian, Tatar, or Bashkir descent; the aim was to search for ethnically specific genetic risk markers for $\mathrm{SZ}$.

In 2010, the RIMG (Tomsk) joined the European Union funded (FP7-HEALTH) ADAMS project, which searched for genomic variations underlying Alzheimer's disease (AD), alcoholism, SZ, and cognition traits. Within ADAMS, the RIMG performed a population genomic study of genetic markers associated with neurological and mental diseases (AD, Parkinson's disease [PD], SZ, and cognitive performance); the study demonstrated considerable between-population variability in allele frequencies across multiple Eurasian populations (eight populations were included, representing Eastern Europe, Central Asia, Northern Asia, and Siberia) [7]. Population differentiation measured by Wright's F statistic (Fst), which corresponds to the proportion of between-population variability in the total genetic variance, varied widely across the loci studied (from 0.006 to 0.146), and the mean Fst for all 55 single nucleotide polymorphisms (SNPs) was 0.045 . The mean Fst for AD (0.029) was substantially lower than for PD (0.044), SZ (0.054), and cognitive performance (0.049). The allele frequencies tended to correlate between populations according to their geographical locations. The data indicated that wide inter-population variation exists in the

\footnotetext{
${ }^{1}$ We will use these institutions' abbreviations in the text below.
} 
frequency of alleles associated with common diseases, even on a sub-continental level [7].

A microarray for genotyping ten SNPs associated with the sporadic form of AD was developed by the Engelhardt Institute of Molecular Biology in collaboration with the RIMG [8, 9].

In a replication study at the RIMG, 50 SNPs found in GWASs of SZ, AD, and cognitive endophenotypes were studied in Russian and Kazakh patients with AD and SZ [10-12]. SNPs in regions of eight genes, including APOE, were associated with $\mathrm{AD}$ in the Russian participants. The associations between 10 genetic markers and SZ were replicated in Russians, and the associations between 8 genetic markers and SZ were replicated in Kazakhs. Among the genetic markers associated with $\mathrm{AD}$ and $\mathrm{SZ}$ in the Russian population, 3 genes were common for both diseases, indicating an overlap of pathogenetic mechanisms between AD and SZ; this overlap is probably mediated by cognitive endophenotypes (manuscript in preparation).

The IBG performed a study in individuals with SZ from the Russian, Tatar, and Bashkir ethnic groups to investigate 88 polymorphisms of 23 candidate genes implicated in neurotransmission and neuronal development. The study found differences in GRIN2B [13], NTRK3, NXPH1 [14], GRIA2 [15], GRIK2, RGS2 [16], and TPH1 [17] between SZ patients from the Russian and Tatar ethnic groups. A further study identified risk markers for unipolar depression in SLC6A4, HTR2A, TPH1, MAOA, NTRK2, NTRK3, NRXN1, NXPH1, and MTHFR in both Russians and Tatars $[18,19]$.

A study performed at the MHRI (Tomsk) showed an association of (N251S)-PIP5K2A with SZ [20]. At PRMU (Nizhny Novgorod), an association study of single-carbon metabolism genes with SZ, the severity of negative and cognitive symptoms, the clinical course of the disease, and the side effects of antipsychotic therapy has been ongoing since 2013 [21, 22].

Genotype-phenotype studies at the Clinical Genetics Laboratory (MHRC) have focused on the clinical characteristics of SZ, in particular on cognitive deficits, a core and enduring feature of the illness. Associations between candidate genes and impairments in short-term and verbal memory and selective attention were identified in large groups of patients with SZ [23-25]. The laboratory also looked for genetic polymorphisms associated with some important but understudied features of social behavior and social cognition in SZ (Machiavellianism, facial emotion recognition, and theory of mind) [26, 27]. Currently, its efforts are concentrated on developing approaches to investigate the genetic background of cognitive reserve and resilience in SZ. Its research also focuses on the relationship between genes involved in inflammation and personality traits that predispose to SZ; the level of premorbid social functioning in SZ patients; the severity of the main clinical syndromes of SZ [28, 29]; and genes that exert a modifying effect on the course, clinical features, and outcome of SZ [30-32].

Research at the Department of Addictions at the BNMRCPN and the Laboratory of Clinical Psychopharmacology of Addictions, First Saint Petersburg Pavlov State Medical University, places great emphasis on identifying genetic variants involved in alcohol and opioid addictions [33-35]. Since 1999, when an association was found between dopamine genes and alcohol dependence in the Russian population [36], the molecular genetics laboratory at the SNMRCPA (Moscow) has focused on genetic risk markers and polygenic risk scores for opioid and alcohol dependence, including severe complications of alcohol withdrawal syndrome, and on the search for genetic markers of possible "hereditary" forms of the disorders and the associated courses, clinical features, and outcomes [37-39].

An RIMG (Tomsk) project funded by the Russian Science Foundation (RSF) aimed to elucidate the link between the genetic components of neuropsychiatric diseases and normal variability in cognitive functions in the elderly. Some alleles and haplotypes predisposing to $\mathrm{AD}$ were found to be associated with a worse cognitive status in elderly people without a diagnosis of AD [40-42]. It is likely that the normal age-dependent variability in cognitive functions can be considered as an endophenotype of AD. Currently, the search for new genetic markers of the variability in cognitive functions is being conducted through exome-wide association studies.

Two sequencing studies at SPBU revealed a list of several ultra-rare or previously unreported variants in several brain-expressed genes in patients with SZ and schizotypy that were absent in healthy controls [43, 44]. Future functional studies will assess the pathogenic role of these variants, including one interesting candidate found to be damaging in silico [45].

Over 1500 children with idiopathic intellectual disability were examined as part of the European Union project "Improving Diagnoses of Mental Retardation in Children in Eastern Europe and Central Asia through Genetic Characterisation and Bioinformatics/Statistics" (CHERISH), and the RIMG identified several novel chromosomal microdeletions and microduplications [46-49]. All clinical and molecular protocols were introduced into the Genetics Clinic of the RIMG in Tomsk and are now available to patients.

In parallel, the Molecular Brain Genetics Laboratory at the MHRC evaluated variomes in children with intellectual disability and revealed a series of previously undescribed genomic and epigenomic abnormalities (i.e., runs of homozygosity affecting imprinted genomic loci) associated with this devastating condition $[50,51]$. 
Since the late 1980s, the Laboratory of Cytogenetics and Genomics of Psychiatric Diseases and the Molecular Brain Genetics Laboratory at the MHRC (Moscow) have focused on studying gene and chromosomal mutations in psychiatric diseases, and in 1998 they entered the chromosome 18 workshop [52]. The laboratories had the original idea to look for brain-specific genetic defects, and they thereby uncovered mosaic chromosome abnormalities in the SZ brain [53], suggested brain-confined mosaicism as a mechanism of mental illness [54] and found somatic mosaicism to be common in autism [55]. Additionally, brain- and chromosome-specific instability (aneuploidy) was reported in SZ [56] and in neurodegenerative diseases (ataxia-telangiectasia and $\mathrm{AD}$ ) [57]. Consequently, chromosome instability (a recognized genetic mechanism of cancer) was shown to underlie neurodegeneration [58]. As a result, the laboratories proposed the DNA replication stress hypothesis of $\mathrm{AD}$, which links the amyloid and cell cycles (the abortive neuronal cell cycle is hypothesized to cause neurodegeneration) [59]. Further studies revealed a link between $\mathrm{AD}$ and aging or cell senescence that was related to chromosome instability [60]. The laboratories' latest studies have shed some light on the genetic mechanisms of comorbidity in psychiatric disorders, which may be associated with similar patterns of brain-specific chromosome instability in at least some cases [61]. Recently, these pioneering efforts were recognized by the "Brain Somatic Mosaicism Network" (https://www.nimh.nih.gov/news/ events/2017/brain-somatic-mosaicism-network-investiga tors-workshop.shtml). Finally, these laboratories identified a treatment for psychiatric diseases associated with chromosomal imbalances (previously incurable conditions) by uncovering pathways disrupted by a genomic pathology that can be corrected by diet and conventional medications [62].

The Clinical Genetics Laboratory at the MHRC (Moscow) is currently studying epigenetic markers associated with neurocognitive deficits in SZ by using the SMRT-BS method, which is based on the third-generation high-throughput sequencing platform PacBio. The first results showed variability in the methylation level of different regions within the promoter of the reelin gene [63].

To study the functional relevance of newly discovered genetic variants for SZ ex vivo, researchers at the MHRC have started to collect primary cell cultures derived from the olfactory epithelium of patients with SZ.

Researchers at the MHRI (Tomsk), in collaboration with the Institute of Physiology, University of Tuebingen (Germany), demonstrated the functional relevance of (N251S)PIP5K2A in SZ via deranged regulation of neuronal KCNQ potassium channels and EAAT3 excitatory amino acid transporters [64, 65]. In collaboration with the Institute of Cytology and Genetics (Novosibirsk, Russia), the researchers at the RIMG (Tomsk) obtained induced pluripotent stem cells (IPSCs) from patients with 3p26.3 microdeletions and microduplications affecting CNTN6, whose role in the pathogenesis of intellectual disability had not been previously described. The IPSCs were further differentiated into cortical neurons, and the researchers found that the CNTN6 expression level from the duplicated allele was significantly decreased, leading to haploinsufficiency [66]. This finding provides a novel molecular explanation for the origin of overlapping clinical and neurodevelopmental features in patients with reciprocal copy number variations.

The Enhancing Neuroimaging Genetics Through Meta Analysis (ENIGMA) network comprises over 30 working groups worldwide (http://enigma.ini.usc.edu/) and includes three groups from Russia that are working on major depressive disorder and SZ: (1) the MHRC (Moscow), (2) the MHRI (Tomsk), and (3) the Scientific Research Institute of Physiology and Basic Medicine (Novosibirsk). These Russian institutions provided MRI data and DNA from patients with major depressive disorder and SZ and from healthy individuals for the genetic association studies of brain abnormalities in these disorders $[67,68]$ and for the studies mapping cortical brain asymmetry in healthy individuals [69].

For the last decade, the Laboratory of Molecular Genetics and Biochemistry (MHRI, Tomsk) has been working in the field of pharmacogenetics of mental and neurodegenerative disorders. They work in collaboration with the Groningen Research Institute of Pharmacy, University of Groningen (Netherlands). The results of the studies in SZ are summarized in Table 1.

The BNMRCPN (Saint Petersburg) performed a study in patients with acute psychosis treated with olanzapine or haloperidol and found no evidence that mRNA levels of the dopamine $\mathrm{D} 4$ receptor and serotonin $2 \mathrm{~A}$ receptor in peripheral blood mononuclear cells are biomarkers of treatment response [70]. Another study in patients with SZ performed at the IBG (Ufa) showed that polymorphism in genes of the serotoninergic and dopaminergic systems affects individual sensitivity to haloperidol [71]. A study at the Molecular Genetics Laboratory of the SNMRCPA (Moscow) in a cohort of inpatients with SZ found that CYP2D6 metabolic activity affects the mean antipsychotic daily dose only in the presence of the DRD2/ANKK1 Taq1A $\mathrm{T}$ allele, but CYP2D6 metabolic activity correlates with the duration of the hospital stay independent of DRD2 Taq1A [72]. A subsequent study revealed that polymorphism of SCL6A3 can affect the safety of haloperidol in patients with alcohol use disorder [73].

Two studies at the MHRI (Tomsk) found that the polymorphisms AKT1 rs1130214 and GSK3B rs334558 are associated with antidepressant treatment response $[74,75]$. 
Table 1 Gene association findings of studies on antipsychotic-induced side effects in Russian inpatients with schizophrenia

\begin{tabular}{|c|c|c|c|c|}
\hline $\begin{array}{l}\text { Sample } \\
\text { size, } N\end{array}$ & $\begin{array}{l}\text { Patients with } \\
\text { side effects, } n\end{array}$ & Gene & Associated allele(s) and genotype(s) & Ref. \\
\hline \multirow[t]{2}{*}{146} & \multirow[t]{2}{*}{43} & DRD3 & Ser9Gly association with TDlt & \multirow[t]{2}{*}[82]{} \\
\hline & & $H T R 2 C$ & Cys23Ser association with TDlt & \\
\hline 146 & 43 & $\mathrm{MnSOD}$ & Ala-9Val association with TDof & {$[83]$} \\
\hline \multirow[t]{2}{*}{401} & \multirow[t]{2}{*}{127} & GRIN2A & $\begin{array}{l}\text { rs1345423 C allele association with TD and TDof; } \\
\text { rs11646587 A allele association with TDof; } \\
\text { rs7206256 A allele association with TDof; } \\
\text { rs7190619 AG genotype association with TDof }\end{array}$ & \multirow[t]{2}{*}{ [84-86] } \\
\hline & & GRIN2B & rs2192970 association with TD & \\
\hline 146 & 43 & CYP17A1 & $\begin{array}{l}\text { Cyp17 (T34C, rs743572) TC or TT genotypes } \\
\text { association with TD }\end{array}$ & {$[87]$} \\
\hline \multirow[t]{2}{*}{319} & \multirow[t]{2}{*}{206} & CYP1A2 & $\begin{array}{l}\text { CYP1A2*1F }(-163 \mathrm{C}>\mathrm{A}, \text { rs } 762551) \text { association with } \\
\text { TD }\end{array}$ & \multirow[t]{2}{*}[88]{} \\
\hline & & $C Y P 2 D 6$ & $\begin{array}{l}\text { CY2D6*4 }(1846 \mathrm{G}>\mathrm{A}) \text { and genotype } \mathrm{A} / \mathrm{A} \\
\text { association with TDlt }\end{array}$ & \\
\hline 465 & 131 & $P I P 5 K 2 A$ & rs10828317 (N251S) association with TD & [89] \\
\hline 146 & 43 & $A D O R A 2 A$ & rs3032740 (2592C/Tins) no association with TD & {$[90]$} \\
\hline 401 & 127 & GRIN2A & $\begin{array}{l}\text { rs } 1345423 \text { association with TD in both Dutch and } \\
\text { Russian patient populations }\end{array}$ & {$[91]$} \\
\hline 446 & 227 & $H T R 2 C$ & $\begin{array}{l}\text { X-chromosome haplotype (rs569959 and } \\
\text { rs17326429) association with HPRL }\end{array}$ & {$[92]$} \\
\hline \multirow[t]{2}{*}{128} & \multirow[t]{2}{*}{66} & $C Y P 2 D 6$ & rs3892097 association with HPRL & \multirow[t]{2}{*}[93]{} \\
\hline & & $H T R 2 C$ & rs6318 association with HPRL & \\
\hline 443 & 227 & $P R L$ & rs1341239 $(-1149 \mathrm{G} / \mathrm{T})$ association with HPRL & [94] \\
\hline
\end{tabular}

$T D$ tardive dyskinesia, TDof orofaciolingual tardive dyskinesia, TDlt limb-truncal tardive dyskinesia, $H P R L$ hyperprolactinemia
A pharmacogenetic component of the collaborative double-blind, double-dummy, placebo-controlled randomized clinical trial of implantable naltrexone vs. oral naltrexone and placebo for opioid dependence (Molecular Genetics Laboratory of the SNMRCPA, Moscow; Department of Addictions, BNMRCPN; the Laboratory of Clinical Psychopharmacology of Addictions, First Saint Petersburg Pavlov State Medical University; and Baylor College of Medicine, TX, USA) showed the joint effect of opioid receptor genes and genes of the dopaminergic system on treatment outcomes [76]. In another study, this collaborative group showed the additive effect of opioid receptor genes and dopaminergic system genes on outcomes of treatment of opioid dependence with oral naltrexone and guanfacine [77].

\section{Opening up new horizons: the Russian National Consortium for Psychiatric Genetics (RNCPG)}

As detailed above, a wide range of high-quality studies have been performed at individual research centers and in "center-to-center" collaborations in Russia, and various centers have participated in international projects. Nevertheless, it became clear that the psychiatric genetic research centers in Russia need to work together even more closely to improve and accelerate development in the field of psychiatric genetics in Russia. The tasks at hand cannot be solved by individual centers working in isolation but warrant a truly collaborative effort that brings together all the centers in a Russian-wide consortium.

The first scientific conference on psychiatric genetics in Russia, "Genetics and epigenetics of mental illnesses," took place in Moscow in November 2017. It was organized by the MHRC and SNMRCPA (Moscow) and the Russian Society of Psychiatrists and supported by the Russian Foundation for Basic Research (RFBR). At this conference, the Russian National Consortium for Psychiatric Genetics (RNCPG) was established and all the primary members wrote the memorandum of understanding. The Consortium is set up as an open organization that will enable collaborations within the Russian Federation and worldwide (http://rncpg.org).

\section{Specific aims and goals of the RNCPG}

The primary goal of the Consortium is to foster a better understanding of the genetic basis of mental illnesses with 
the aim to improve their prevention and treatment in the population of the Russian Federation.

To achieve this goal, the Consortium members have agreed to:

1. unite the scientific, clinical, and technological capabilities of the leading Russian research centers in the field of psychiatric genetics;

2. establish and maintain Russia's largest collection of biomaterials from people with mental illnesses and population-matched controls. In the initial stage, i.e., by 2020 , we expect to collect biomaterials from the following numbers of people: $\sim 15,000$ with SZ, $\sim 10,000$ with major depressive disorder, $\sim 3000$ with $\mathrm{BD}, \sim 8000$ with alcohol and drug dependence, $\sim 3000$ with eating disorders, and $\sim 20,000$ healthy controls;

3 . ensure that genetic and biomedical interdisciplinary research into the etiology, pathogenesis, and efficacy of pharmacotherapy of mental diseases in the population of Russia is performed according to modern scientific and technological standards;

4. facilitate the participation of Russian scientists and studies in the Russian population in international collaborations;

5. develop guidelines for clinical practice that apply the results of genetic studies in the Russian population.

Our current priorities in the Consortium are as follows:

1. Integrate genomic, pharmacogenomic, and epigenomic projects within the Consortium, with an emphasis on the importance of prospective studies; provide opportunities for biological research beyond genomics.

2. Integrate epidemiological studies of psychiatric disorders that compare Russians with ethnic groups from other countries; efficiently account for ethnic heterogeneity.

3. Enable the standardized assessment of a wide range of both traditional and novel clinical phenotypes; ensure the highest standards of scientific practice at all levels of psychiatric genetic research and facilitate true interdisciplinary research.

We are currently considering reorganizing the structure of the RNCPG to better correspond with our goals. We propose that the RNCPG should include six scientific research centers, each with their own psychiatric hospital; eight psychiatric hospitals that act as RNCPG partners; the SPBU Biobank, which is the technological hub of the RNCPG; and theInstitute of Translational Biomedicine in SPBU, the translational core of the RNCPG. All these units will need to work together in the RNCPG to generate high-quality genomic data that can be quickly translated into clinical practice and enable the development of treatment guidelines.

Today, the RNCPG comprises the following research centers: MHRC; SNMRCPA; MHRI; BNMRCPN; IBG; and PRMU. It represents a voluntary association of research scientists and physicians that allows psychiatrists and geneticists to collaborate closely from the initial planning of projects to data processing and final discussions. These features enable the RNCPG to construct high quality, correct phenotypes for a broad spectrum of diseases and disorders. As a result, in May 2018 the Consortium became a special section in the Russian Society of Psychiatrists.

No special diagnostic groups are planned, and every collaboration project inside the Consortium is flexible and open to members and associated participants.

Most of the centers in the Consortium have their own psychiatric hospital. The Consortium already collaborates with the leading psychiatric hospitals in the Russian Federation; these eight hospitals have more than 10,000 inpatient beds and together treat more than 12,000 outpatients per year. In addition, six hospitals from other regions of the country have agreed to collaborate with the Consortium.

The Consortium operates on the basis of the international principles of medical ethics, and all biosamples and participant data are used only after informed consent has been obtained.

All the biomaterials will be processed inside the Russian Federation according to the law, regulations, and policies related to human biomaterial. The fully coded and anonymized data sharing procedure will be included in specific protocols in every international collaboration project.

\section{SPBU Biobank as the technological hub for the RNCPG}

Founded in 2015, the biobank of SPBU focuses on complex biomedical research projects on human health and longevity. Since the year it was founded, the biobank has been involved in the project "Genome of Russia," which aims to analyze the whole-genome sequence of 2500 men and women from the various regions of Russia.

SPBU biobank joined the RNCPG when it was founded at the end of 2017 and began processing and providing long-term storage of blood and DNA samples for the Consortium. Before then, there was no biobank in Russia specializing in the standardized collection and storage of biological samples from patients with psychiatric diseases. Today, the SPBU biobank constitutes the Consortium's technological core and hub for biosamples and serves as the central unit for storing and processing all the biomaterials collected at the member centers. Processing includes genotyping, sequencing, transcriptome and epigenome analysis, metabolomics, and a wide array of other state-of-the-art 
analyses. Like all biobanks, SPBU biobank will facilitate medical research into psychiatric diseases by providing biological samples along with the associated clinical data, including medical and genealogical information and information on environmental factors, such as descriptors of an individual's lifestyle.

The computational infrastructure necessary for the bioinformatical analysis of large volumes of genetic information is available at the Computational Center of the Technical Park of SPBU, which has been routinely performing such analyses of the data from the SPBU Biobank since 2015 [78, 79].

\section{Institute of Translational Biomedicine (SPBU) as a translational core for the RNCPG}

The Institute of Translational Biomedicine, SPBU, is currently developing transgenic animal models of neuropsychiatric disorders. It is collaborating closely with SPBU biobank and plans to become a translational core for the Consortium. The modern animal facility provides standard pathogen-free conditions and allows neuropsychiatric disorders to be modeled through targeted mutations in neurotransmitter systems. Several transgenic mouse and rat models are available in the facility, including recently created novel models of enhanced central dopaminergic function based on knockout of the dopamine transporter (DAT) gene in rats [80]. This model has translational relevance to brain disorders classically associated with the enhanced dopaminergic function, such as $\mathrm{SZ}$ and attention deficit hyperactivity disorder.

\section{The RNCPG: getting started}

In 2017, the RNCPG started collaborating with the PGC on a GWAS in SZ, and to date it has genotyped $505 \mathrm{SZ}$ patients and 503 population-matched controls with the Infinium Global Screening Array. Next, we plan to perform the first GWAS in a Russian population with SZ.

In 2019, the RNCPG intends to start working with the PGC on a GWAS of alcohol dependence, and in 2020, on major depressive disorder; these will be the first GWASs of these disorders in the Russian population. In 2019, the RNCPG also plans to start collaborating with ConLiGen (www.conligen.org), the International Consortium on Lithium Genetics [81].

\section{The major planned projects of RNCPG}

We are ready to start planning some linked framework projects that are based on modern concepts in both clinical psychiatry and human genomics. The main part of these projects should be prospective and multicenter. We are interested in any kind of international collaborative project and welcome colleagues to join us.

\section{Deep and precise phenotyping}

Another planned project is the deep and precise phenotyping of patients, their families, and high-risk individuals, with a main focus on patients with first-episode SZ. All the available information on multidimensional phenotypes (social and demographic, family and family history, personality, psychometric, clinical, psychiatric and somatic comorbidity, cognitive, laboratory, and neuroimaging information, etc.) will be assessed, and topics of interest will include gene-environment interactions. We will analyze genetic influences on disease course, specific features of disease manifestation, effects and side effects of treatment, remission, and outcome. In 2019, the RNCPG will join forces with the Institute of Psychiatric Phenomics and Genomics (IPPG) at the University Hospital of the LMU Munich (Germany) to perform longitudinal research on recovery-related phenotypes.

\section{Pharmacogenomics of antipsychotics and antidepressants}

In addition, we plan to study the pharmacogenomics of antipsychotics and antidepressants, i.e., "treatment genomics". This project will be closely linked to the deep and precise phenotyping project and will focus on the genetic control of treatment effects and side effects, with the following key topics: (1) pharmacotherapy, with a special focus on long-acting and depot preparations; (2) transcranial magnetic stimulation (TMS) and electroconvulsive therapy (ECT); (3) psychotherapy alone and in combination with pharmacotherapy.

The first prospective study on treatment-resistant major depressive disorder in the Russian population was started in 2017 as a project within the RNCPG. This naturalistic multicenter study is focusing on mechanisms of treatment resistance rather than on the efficacy of the selected drugs and augmentation therapy. Up to 3000 patients who fulfil ICD-10 diagnostic criteria for a major depressive episode (F32) or major depressive disorder (F33) are to be evaluated. It is planned that the first GWAS in major depressive disorder in the Russian population will be part of this project.

In all of our projects, special attention will be paid to metabolic side effects of psychopharmacotherapy that affect the development and outcome of comorbid somatic diseases in psychiatric patients. 


\section{Psychiatric and somatic comorbidity}

In our planned project on psychiatric and somatic comorbidity, we will take a cross-disorder approach. This project will be linked to the "deep and precise phenotyping" and "treatment genomics" projects and focus on the genetic basis of pathogenetic links between common somatic and psychiatric diseases (depression). The specific aim of this project is to use genomics and phenomics data to evaluate whether there is a bidirectional and/or causal relationship between depression and somatic disease.

\section{Brain biobank}

So far, we have only taken the initial steps to start collecting brain samples at the SPBU biobank, and we now plan to increase efforts within the consortium to expand the collection of postmortem brains from psychiatric patients. Currently, we are in the preparatory stage for developing protocols for collecting and storing various postmortem specimens, including brain tissue biopsies. We plan to start collaborations with the Neurobiobank in Munich, Germany (https://www.neuropathologie.med.uni-muenchen.de/ neurobiobank_muenchen/index.html) and the Douglas-Bell Canada Brain Bank in Montreal, Canada (www.douglasbra inbank.ca).

\section{Challenges to address in the RNCPG}

The establishment of the RNCPG is the first but important initial step in the long road to achieve our aims and goals. This initiative is the result of our understanding that only joint efforts can enable us to promote and develop psychiatric genetics and genomics in the Russian Federation. We wish to highlight the following are specific challenges facing our Consortium:

1. Population and geography. The Russian Federation covers a large geographical area that is located in two continents: Europe and Asia. We need to study psychiatric genetics in heterogeneous populations in historically mixed (European-Asian) regions (VolgaUral Region, Siberia) that are locally diverse and in more homogenous parts of the country (European region) and thereby pay special attention to the cultural diversity.

2. Legislation regulation. To date, the Russian Federation has no specific legislation on the biobanking of human biomaterial, and there are only separate documents regulating the collection, storage, and use of biological samples for certain practical medical purposes (transplantation, reproductive technologies).
3. Infrastructure. The further development of our Consortium requires a lot of work to build the next generation of modern scientific infrastructure in the Russian Federation. To address this challenge, we have designed a detailed road map for the initial period up to 2020 on the basis of the available potential of the research centers, St. Petersburg University and the Biobank.

4. Personnel and educational programs. The structure of our Consortium needs qualified and experienced personnel in the fields of psychiatry, genetics, bioinformatics, and scientific management. An important goal of the Consortium is to provide adequate training for young mental health care professionals. The main tasks of the unified training programs are to provide recent data on psychiatric genetics and neuropsychiatric research and to exchange study experiences with different centers, regions, and countries. Currently, training is offered as regular annual meetings, conferences, and schools for young scientists and lectures that aim to broaden the understanding of psychiatric genetics and provide education on how to organize clinical trials, develop study protocols and write scientific publications. Most centers already have the resources to provide regular on-site training for young professionals. Trainees are provided with opportunities for integrative learning through visits to different centers and by sharing their experiences. Another important aspect is the constant communication between the trainers. We plan to increase the number of lectures and round tables and will hold annual lectures to provide updates on the work of the Consortium and its current projects and on changes in research methods. In addition, we are considering holding integrated telecommunication conferences to facilitate long-term, ongoing training. One of the important current objectives of the Consortium is to arrange adequate financial support for the continuing education efforts and to involve young specialists in Consortium projects.

5. Development of international collaborations. Most of the RNCPG members have a history of successful international collaborations, which provides us with opportunities to develop new collaboration projects worldwide. The Consortium was founded as an open system, and our standards for research design, precision phenotyping, and genetic analysis fully correspond with international ones. All the projects within the RNCPG are flexible enough to enable them to be harmonized with and adjusted to the most modern projects in the field of psychiatric genetics in other countries. We are 
prepared for any kinds of scientific collaborations and would like to invite all colleagues to participate in joint research programs.

6. Enlarging the collections of samples and increasing funding. The RNCPG members are currently funded by government foundation agencies, mostly the Russian Foundation for Basic Research (RFBR) and the Russian Science Foundation (RSF). This funding is for the RNCPG's own projects within the framework of its goals. Our plans to substantially increase the size of our collections of samples will require increased funding for storage, processing, and data analysis. The successful outcome of the initial steps of the RNCPG (2018-2020) will help us to generate new opportunities for large research projects for the whole Consortium.

\section{Conclusion}

The RNCPG has all the capabilities to achieve its goals. Its members are open to any kinds of collaboration, both within Russia and internationally, that are performed according to the principles of scientific partnership. We believe that high quality genetic, genomic, and pharmacogenetic data from the Russian population are of great value and will be extremely useful for the psychiatric genetics community to allow sustained progress in this fascinating area of human genetics.

Acknowledgements The results presented in this paper were supported by grants of the 7th Framework Program of the European Union (\#223692, CHERISH; \#242257, ADAMS: "Genomic variations underlying common neuropsychiatric diseases and diseaserelated cognitive traits in different human populations", I.N.L., V. A.S., A.E.G., E.K.K.); the Russian Science Foundation (\#14-3500023: "Laboratory of pharmacogenetic research on personalized therapy of mental and neurodegenerative disorders", O.Yu.F., S.A. I.; \#17-75-10055: "Pharmacogenetics of tardive dyskinesia in schizophrenia: the role of polymorphisms of muscarinic, adrenergic and glutamate receptor genes", S.A.I.; \#16-15-00056: "Epigenetics of cognitive deficits in schizophrenia," V.E.G; \#14-15-00904: "Antipsychotic drugs: Development of personalized approaches to therapy based on individual characteristics of receptors of neurotransmittors on human lymphocytes", E.M.K., R.F.N.; \#14-1500772: "Cell and Molecular Mechanisms of Pathogenesis of Chromosomal Diseases," I.N.L.; \#14-50-00069: "Translational biomedicine in SPBU", R.R.G.; and \#16-15-00020: "Genetic basis of the cognitive functions variability in the elderly and in patients with Alzheimer's disease", V.A.S.); the Ministry of Education and Science of the Russian Federation (\#02.740.11.5035: "Genes responsible for cerebral lateralization in normal development and in schizophrenia" and \#14.740.11.0929: "Role of several genes involved in WNT and NODAL molecular pathways in cerebral lateralization and in schizophrenia", A.L.), and the Russian Foundation for Basic Research (\#12-04-00595: "Population genomics of neuro-psychiatric diseases in populations of Russia", V.A.S.; \#11- 04-01102-a: "Study of association of PIP5K2A gene polymorphisms with socially significant mental and behavioral disorders", $\mathrm{O}$. Yu.F., S.A.I.; \#12-04-33072: "The pathogenesis of movement antipsychotic-induced disorders in patients with endogenous mental disorders: the role of pharmacogenetic factors", O.Yu.F., S.A.I.; \#17-29-06035: "New approaches to the pharmacogenetics of antipsychotic-induced hyperprolactinaemia in patients with schizophrenia," O.Yu.F., S.A.I.; \#18-315-20019: "New approaches to the genetics of clinical polymorphism and neurocognitive deficits in schizophrenia", O.Yu.F., S.A.I.; \#10-04-00300a: "A role of the WNT pathway components in the human brain left-right asymmetry formation during embryogenesis: schizophrenia as a model", A.L.; and \#17-29-02205: "Development of a molecular-genetic panel of depressive disorders based on polymorphisms of the genes of neuronal kinases, neurotrophic proteins and genes of the serotonergic system," N.A.B., S.A.I.). The authors thank Jacquie Klesing, Board-certified Editor in the Life Sciences (ELS), for editing assistance with the manuscript.

\section{Compliance with ethical standards}

Conflict of interest The authors declare that they have no conflict of interest.

Publisher's note: Springer Nature remains neutral with regard to jurisdictional claims in published maps and institutional affiliations.

Open Access This article is licensed under a Creative Commons Attribution 4.0 International License, which permits use, sharing, adaptation, distribution and reproduction in any medium or format, as long as you give appropriate credit to the original author(s) and the source, provide a link to the Creative Commons license, and indicate if changes were made. The images or other third party material in this article are included in the article's Creative Commons license, unless indicated otherwise in a credit line to the material. If material is not included in the article's Creative Commons license and your intended use is not permitted by statutory regulation or exceeds the permitted use, you will need to obtain permission directly from the copyright holder. To view a copy of this license, visit http://creativecommons. org/licenses/by/4.0/.

\section{References}

1. Rogaev E. Academic psychiatry in Russia: new times, new challenges. Mol Psychiatry. 2004;9:975-6.

2. Stefansson H, Ophoff RA, Steinberg S, Andreassen OA, Cichon $\mathrm{S}$, Rujescu D, et al. Common variants conferring risk of schizophrenia. Nature. 2009;460:744-7.

3. Schizophrenia Psychiatric Genome-Wide Association Study (GWAS) Consortium. Genome-wide association study identifies five new schizophrenia loci. Nat Genet. 2011;43:969-76.

4. Schizophrenia Working Group of the Psychiatric Genomics Consortium. Biological insights from 108 schizophreniaassociated genetic loci. Nature. 2014;511:421-7.

5. Mühleisen TW, Leber M, Schulze TG, Strohmaier J, Degenhardt F, Treutlein J, et al. Genome-wide association study reveals two new risk loci for bipolar disorder. Nat Commun. 2014;5:3339.

6. Pardiñas AF, Holmans P, Pocklington AJ, Escott-Price V, Ripke $\mathrm{S}$, Carrera $\mathrm{N}$ et al. Common schizophrenia alleles are enriched in mutation-intolerant genes and in regions under strong background selection. Nat Genet 2018. https://doi.org/10.1038/s41588-0180059-2. 
7. Stepanov VA, Marusin AV, Simonova K. Genetic variability in common mental and neurological disorders in North Eurasia. Clin Biochem. 2011; 44, Supplement: S27-S28.

8. Golenkina SA, Gol'tsov AIu, Kuznetsova IL, Grigorenko AP, Andreeva TV, Reshetov DA, et al. Analysis of clusterin gene (CLU/APOJ) polymorphism in Alzheimer's disease patients and in normal cohorts from Russian populations. Mol Biol (Mosk). 2010;44:620-6.

9. Nizamutdinov II, Andreeva TV, Stepanov VA, Marusin AV, Rogaev EI, Zasedatelev AS, et al. Biochip for determination of genetic markers of sporadic Alzheimer's disease in the Russian Slavic population. Mol Biol (Mosk). 2013;47:949-58.

10. Stepanov VA, Bocharova AV, Marusin AV, Zhukova NG, Alifirova VM, Zhukova IA. Replicative association analysis of genetic markers of cognitive traits with Alzheimer's disease in a Russian population. Mol Biol (Mosk). 2014;48:952-62.

11. Stepanov VA, Bocharova AV, Saduakassova KZ, Marusin AV, Koneva LA, Vagaitseva KV, et al. Replicative study of susceptibility to childhood-onset schizophrenia in Kazakhs. Genetika. 2015;51:227-35.

12. Bocharova AV, Stepanov VA, Marusin AV, Kharkov VN, Vagaitseva KV, Fedorenko OY, et al. Association study of genetic markers of schizophrenia and its cognitive endophenotypes. Genetika. 2017;53:100-8.

13. Gareeva AE, Zakirov DF, Khusnutdinova EK. Association polymorphic variants of GRIN2B gene with paranoid schizophrenia and response to common neuroleptics in Russians and Tatars from Bashkortostan Republic. Russ J Genet. 2013;49:962-8.

14. Gareeva AE, Traks T, Koks S, Khusnutdinova EK. The Role of Neurotrophins and Neurexins Genes in the Risk of Paranoid Schizophrenia in Russians and Tatars. Russ J Genet. 2015; 51:799-811.

15. Gareeva AE, Khusnutdinova EK. Glutamate receptors genes polymorphism and the risk of paranoid schizophrenia in Russians and Tatars from the Republic of Bashkortostan. Mol Biol. 2014;48:671-80.

16. Gareeva AE, Zakirov DF, Valinurov RG, Khusnutdinova EK. Polymorphism of RGS2 gene: genetic markers of risk for schizophrenia and pharmacogenetic markers of typical neuroleptics efficiency. Mol Biol. 2013;47:814-20.

17. Galaktionova DYu, Gareeva AE, Khusnutdinova EK, Nasedkina TV. The association of polymorphisms in SLC18A1, TPH1 and RELN genes with risk of paranoid schizophrenia. Mol Biol. 2014;48:546-55.

18. Noskova T, Pivac N, Nedic G, Kazantseva A, Gaysina D, Faskhutdinova $\mathrm{G}$, et al. Ethnic differences in the serotonin transporter polymorphism (5-HTTLPR) in several European populations. Prog Neuropsychopharmacol Biol Psychiatry. 2008;32:1735-9.

19. Noskova TG, Kazantseva AV, Gareeva AE, Găsina DA, Tuktarova SU, Khusnutdinova EK. association of several polymorphic loci of serotoninergic genes with unipolar depression. Russ $\mathbf{J}$ Genet. 2009;45:742-8.

20. Fedorenko OYu, Rudikov EV, Gavrilova VA, Boiarko EG, Semke AV, Ivanova SA. Association of (N251S)-PIP5K2A with schizophrenic disorders: a study of the Russian population of Siberia. Zh Nevrol Psikhiatr Im S S Korsakova. 2013;113:58-61.

21. Zhilyaeva TV, Sergeeva AV, Blagonravova AS, Kasimova LN. Psychopathological characteristics and social functioning of the schizophrenic patients with the $\mathrm{T}$ allele of the MTHFR677C $>\mathrm{T}$ polymorphism. Zh Nevrol Psikhiatr Im S S Korsakova. 2016;116:5-11.

22. Zhilyaeva TV, Sergeeva AV, Blagonravova AS, Kasimova LN, Kuznetsov KV, Golovanova VI, et al. Association study of methylenetetrahydrofolate reductase genetic polymorphism $677 \mathrm{C}>\mathrm{T}$ with schizophrenia in hospitalized patients in population of European Russia. Asian J Psychiatr. 2018;32:29-33.
23. Alfimova MV, Monakhov MV, Abramova LI, Golubev SA, Golimbet VE. Polymorphism of serotonin receptor genes (5HTR2A) and dysbindin (DTNBP1) and individual components of short-term verbal memory processes in schizophrenia. Neurosci Behav Physiol. 2010;40:934-40.

24. Golimbet VE, Alfimova MV, Gritsenko IK, Lezheiko TV, Lavrushina OM, Abramova LI, et al. Association between a synaptosomal protein (SNAP-25) gene polymorphism and verbal memory and attention in patients with endogenous psychoses and mentally healthy subjects. Neurosci Behav Physiol. 2010;40: 461-5.

25. Golimbet VE, Lebedeva IS, Korovaitseva GI, Lezheiko TV, Abramova LI, Kaleda VG, et al. The Cys allele (the Ser311Cys polymorphism) of the dopamine D2 receptor is associated with schizophrenia and impairments to selective attention in patients. Neurosci Behav Physiol. 2011;41:22-24.

26. Alfimova MV, Golimbet VE, Korovaitseva GI, Abramova LI, Kaleda VG. Association between serotonin receptor 2C gene Cys23Ser polymorphism and social behavior in schizophrenia patients and healthy individuals. Russ J Genet. 2015;51:198-203.

27. Golimbet V, Alfimova M, Abramova L, Kaleda V, Gritsenko I. Arginine vasopressin 1a receptor RS3 promoter microsatellites in schizophrenia: a study of the effect of the "risk" allele on clinical symptoms and facial affect recognition. Psychiatry Res. 2015;225:739-40.

28. Alfimova MV, Golimbet VE, Lezheiko TV, Kondrat'ev NV. Association of -717A $>$ G Polymorphism in the C-Reactive Protein Gene $(C R P)$ with Schizotypal Personality Traits. Bull Exp Biol Med. 2016;162:86-88.

29. Alfimova MV, Korovaitseva GI, Lezheiko TV, Golimbet VE. Interaction Effects of Season of Birth and Cytokine Genes on Schizotypal Traits in the General Population. Schizophr Res Treat. 2017;2017:5763094.

30. Golimbet VE, Alfimova MV, Korovaitseva GI, Lezheiko TV. Modulating effect of Val66Met polymorphism of brain-derived neurotrophic factor gene on clinical and psychological characteristics of patients with schizophrenia. Mol Biol. 2014;48: 69-74.

31. Golimbet V, Alfimova M, Abramova L, Kaleda V, Gritsenko I. Arginine vasopressin 1a receptor RS3 promoter microsatellites in schizophrenia: a study of the effect of the "risk" allele on clinical symptoms and facial affect recognition. Psychiatry Res. 2015;225:739-40.

32. Golimbet V, Korovaitseva G, Lezheiko T, Abramova LI, Kaleda VG. The serotonin transporter gene 5-HTTLPR polymorphism is associated with affective psychoses but not with schizophrenia: A large-scale study in the Russian population. J Affect Disord. 2017;208:604-9.

33. Lappalainen J, Krupitsky E, Remizov M, Pchelina S, Taraskina A, Zvartau E, et al. Association between alcoholism and gammaamino butyric acid alpha2 receptor subtype in a Russian population. Alcohol Clin Exp Res. 2005;29:493-8.

34. Zhang H, Luo X, Kranzler HR, Lappalainen J, Yang BZ, Krupitsky E, et al. Association between two mu-opioid receptor gene (OPRM1) haplotype blocks and drug or alcohol dependence. Hum Mol Genet. 2006;15:807-19.

35. Lappalainen J, Krupitsky E, Kranzler HR, Luo X, Remizov M, Pchelina S, et al. Mutation screen of the GAD2 gene and association study of alcoholism in three populations. Am J Med Genet B Neuropsychiatr Genet. 2007;144B:183-92.

36. Ovchinnikov IV, Druzina E, Ovtchinnikova O, Zagorovskaya T, Nebarakova T, Anokhina IP. Polymorphism of dopamine D2 and D4 receptor genes and Slavic-surnamed alcoholic patients. Addict Biol. 1999;4(4):399-404.

37. Kibitov AO, Voskoboeva EIu, Brodianskiǔ VM, Chuprova NA, Smirnova EV. Association study of the Val158Met polymorphism 
of the catechol-O-methyltransferase gene and alcoholism and heroin dependence: the role of a family history. Zh Nevrol Psikhiatr Im S S Korsakova. 2010;110:84-88.

38. Ivashchenko DV, Shuvalov SA, Chuprova NA, Kibitov AO. The association of polymorphisms in DAT (40 bp VNTR, C>T 3'UTR) and $D B H(-1021 \mathrm{C} / \mathrm{T})$ genes with the severe complications of alcohol withdrawal state. Psychiatr Genet. 2015;25: $268-9$.

39. Kibitov AO, Ivashchenko DV, Brodyansky VM, Chuprova NA, Shuvalov SA. Combination of DAT and $D B H$ gene polymorphisms with a family history of alcohol use disorders increases the risk of withdrawal seizures and delirium tremens during alcohol withdrawal in alcohol-dependent men. Zh Nevrol Psikhiatr Im S S Korsakova. 2016;116:68-80.

40. Stepanov VA, Marusin AV, Vagaitseva KV, Bocharova AV, Makeeva OA. Genetic Variants in CSMD1 Gene Are Associated with Cognitive Performance in Normal Elderly Population. Genet Res Int. 2017;2017:6293826.

41. Stepanov VA, Vagaytseva K, Bocharova A, Marusin A, Markova $\mathrm{V}$, Minaycheva L, et al. Analysis of association of genetic markers in LUZP2 and FXBO40 genes with the normal variability in cognitive performance in the elderly. Int J Alzheimers Dis. 2018; Article ID 2686045, 7.

42. Bocharova AV, Vagaitseva KV, Makeeva OA, Marusin AV, Stepanov VA. Frequencies of alleles, genotypes and haplotypes of two polymorphisms in the clusterin gene in the Russian elderly population categorized by cognitive performance. Data Brief. 2017;16:775-9.

43. Levchenko A, Davtian S, Petrova N, Malashichev Y. Sequencing of five left-right cerebral asymmetry genes in a cohort of schizophrenia and schizotypal disorder patients from Russia. Psychiatr Genet. 2014;24:75-80.

44. Beaulieu JM, Gainetdinov RR, Caron MG. Akt/GSK3 signaling in the action of psychotropic drugs. Annu Rev Pharmacol Toxicol. 2009;49:327-47. (2009)

45. Levchenko A, Davtian S, Freylichman O, Zagrivnaya M, Kostareva A, Malashichev Y. Beta-catenin in schizophrenia: possibly deleterious novel mutation. Psychiatry Res. 2015;228:843-8.

46. Kashevarova AA, Nazarenko LP, Skryabin NA, Salyukova OA, Chechetkina NN, Tolmacheva EN, et al. Array CGH analysis of a cohort of Russian patients with intellectual disability. Gene. 2014;536:145-50.

47. Kashevarova AA, Nazarenko LP, Schultz-Pedersen S, Skryabin NA, Salyukova OA, Chechetkina NN, et al. Single gene microdeletions and microduplication of 3p26.3 in three unrelated families: CNTN6 as a new candidate gene for intellectual disability. Mol Cytogenet. 2014;7:97.

48. Kashevarova AA, Belyaeva EO, Nikonov AM, Plotnikova OV, Skryabin NA, Nikitina TV, et al. Compound phenotype in a girl with $\mathrm{r}(22)$, concomitant microdeletion 22q13.32-q13.33 and mosaic monosomy 22. Mol Cytogenet. 2018;11:26.

49. Lebedev IN, Nazarenko LP, Skryabin NA, Babushkina NP, Kashevarova AA. A de novo microtriplication at 4q21.21-q21.22 in a patient with a vascular malignant hemangioma, elongated sigmoid colon, developmental delay, and absence of speech. Am J Med Genet A. 2016;170A:2089-96.

50. Iourov IY, Vorsanova SG, Kurinnaia OS, Zelenova MA, Silvanovich AP, Yurov YB. Molecular karyotyping by array CGH in a Russian cohort of children with intellectual disability, autism, epilepsy and congenital anomalies. Mol Cytogenet. 2012;5(1):46.

51. Iourov IY, Vorsanova SG, Korostelev SA, Zelenova MA, Yurov YB. Long contiguous stretches of homozygosity spanning shortly the imprinted loci are associated with intellectual disability, autism and/or epilepsy. Mol Cytogenet. 2015;8(1):77.

52. Kennedy JL, Basile VS, Macciardi FM, Detera-Wadleigh S, Evans KL, Holmans PA, et al. Chromosome 4 workshop summary: Sixth World Congress on Psychiatric Genetics, Bonn, Germany, October 6-10, 1998. Am J Med Genet. 1999;88:224-8.

53. Yurov YB, Vostrikov VM, Vorsanova SG, Monakhov VV, Iourov IY. Multicolor fluorescent in situ hybridization on post-mortem brain in schizophrenia as an approach for identification of lowlevel chromosomal aneuploidy in neuropsychiatric diseases. Brain Dev. 2001;23:S186-190.

54. Iourov IY, Vorsanova SG, Yurov YB. Chromosomal variation in mammalian neuronal cells: known facts and attractive hypotheses. Int Rev Cytol. 2006;249:143-91.

55. Yurov YB, Vorsanova SG, Iourov IY, Demidova IA, Beresheva AK, Kravetz VS, et al. Unexplained autism is frequently associated with low-level mosaic aneuploidy. J Med Genet. 2007;44:521-5.

56. Yurov YB, Iourov IY, Vorsanova SG, Demidova IA, Kravetz VS, Beresheva AK, et al. The schizophrenia brain exhibits low-level aneuploidy involving chromosome 1. Schizophr Res. 2008;98:139-47.

57. Iourov IY, Vorsanova SG, Liehr T, Yurov YB. Aneuploidy in the normal, Alzheimer's disease and ataxia-telangiectasia brain: differential expression and pathological meaning. Neurobiol Dis. 2009;34:212-20.

58. Iourov IY, Vorsanova SG, Liehr T, Kolotii AD, Yurov YB. Increased chromosome instability dramatically disrupts neural genome integrity and mediates cerebellar degeneration in the ataxia-telangiectasia brain. Hum Mol Genet. 2009;18:2656-69.

59. Yurov YB, Vorsanova SG, Iourov IY. The DNA replication stress hypothesis of Alzheimer's disease. Sci World J. 2011;11: 2602-12.

60. Yurov YB, Vorsanova SG, Liehr T, Kolotii AD, Iourov IY. X chromosome aneuploidy in the Alzheimer's disease brain. Mol Cytogenet. 2014;7:20.

61. Yurov YB, Vorsanova SG, Demidova IA, Vorsanova SG, Demidova IA, Kolotii AD, et al. Mosaic brain aneuploidy in mental illnesses: an association of low-level post-zygotic aneuploidy with schizophrenia and comorbid psychiatric disorders. Curr Genom. 2018;19:163-72.

62. Iourov IY, Vorsanova SG, Voinova VY, Yurov YB. 3p22.1p21.31 microdeletion identifies CCK as Asperger syndrome candidate gene and shows the way for therapeutic strategies in chromosome imbalances. Mol Cytogenet. 2015;8:82.

63. Alfimova MV, Kondratiev NV, Golov AK, Golimbet VE. Methylation of the reelin gene promoter in peripheral blood and its relationship with cognitive performance of schizophrenic patients. Mol Biol. 2018;5:676-85.

64. Fedorenko O, Strutz-Seebohm N, Henrion U, Ureche O, Seebohm G, Lang FA, et al. Schizophrenia-linked mutation in PIP5K2A fails to activate neuronal M-channels in Xenopus oocytes. Psychopharmacol (Berl). 2008;199:47-54.

65. Fedorenko O, Tang C, Sopjani M, Föller M, Gehring EM, StrutzSeebohm N, et al. PIP5K2A-dependent regulation of excitatory amino acid transporter EAAT3. Psychopharmacol (Berl). 2009;206:429-35.

66. Gridina MM, Matveeva NM, Fishman VS, Menzorov AG, Kizilova HA, Beregovoy NA, et al. Allele-specific biased expression of the CNTN6 gene in iPS cell-derived neurons from a patient with intellectual disability and 3p26.3 microduplication involving the CNTN6 gene. Mol Neurobiol 2018;55:6533-46.

67. Schmaal L, Hibar DP, Sämann PG, Hall GB, Baune BT, Jahanshad N, et al. Cortical abnormalities in adults and adolescents with major depression based on brain scans from 20 cohorts worldwide in the ENIGMA Major Depressive Disorder Working Group. Mol Psychiatry. 2017;22:900-9.

68. van Erp TGM, Walton E, Hibar DP, Schmaal L, Jiang W, Glahn DC, et al. Cortical brain abnormalities in 4474 individuals with Schizophrenia and 5098 Control Subjects Via The Enhancing 
Neuro Imaging Genetics Through Meta Analysis (ENIGMA) Consortium. Biol Psychiatry. 2018; pii: S0006-3223(18)31517-8. https://doi.org/10.1016/j.biopsych.2018.04.023.

69. Kong XZ, Mathias SR, Guadalupe T, ENIGMA Laterality Working Group, Glahn DC, Franke B, et al. Mapping cortical brain asymmetry in 17,141 healthy individuals worldwide via the ENIGMA Consortium. Proc Natl Acad Sci USA. 2018;115(22): E5154-E5163.

70. Taraskina AE, Nasyrova RF, Zabotina AM, Sosin DN, Sosina KA, Ershov EE, et al. Potential diagnostic markers of olanzapine efficiency for acute psychosis: a focus on peripheral biogenic amines. BMC Psychiatry. 2017;17:394.

71. Gareeva AE, Kinyasheva KO, Galaktionova DYu, Sabirov ET, Valinurov RG, Chudinov AV, et al. Polymorphism of brain neurotransmitter system genes: search for pharmacogenetic markers of haloperidol efficiency in Russians and Tatars. Mol Biol. 2015;49:858-66.

72. Kurylev AA, Brodyansky VM, Andreev BV, Kibitov AO, Limankin OV, Mosolov SN. The combined effect of CYP2D6 and DRD2 TAQ1A polymorphisms on the antipsychotics daily doses and hospital stay duration in schizophrenia inpatients (observational naturalistic study). Psychiatr Danub. 2018;30 (2):160-89.

73. Zastrozhin MS, Brodyansky VM, Skryabin VY, Grishina EA, Ivashchenko DV, Ryzhikova KA, et al. Pharmacodynamic genetic polymorphisms affect adverse drug reactions of haloperidol in patients with alcohol-use disorder. Pharmgenomics Pers Med. 2017;10:209-15.

74. Losenkov IS, Vyalova NM, Simutkin GG, Bokhan NA, Ivanova SA. An association of $A K T 1$ gene polymorphism with antidepressant treatment response. World $\mathrm{J}$ Biol Psychiatry. 2016;17:239-42.

75. Levchenko A, Losenkov IS, Vyalova NM, Simutkin GG, Bokhan NA, Wilffert B, et al. The functional variant rs334558 of GSK3B is associated with remission in patients with depressive disorders. Pharmgenomics Pers Med. 2018;11:121-6.

76. Krupitsky EM, Kibitov AO, Blokhina EA, Verbitskaya EV, Brodyansky V, Alekseeva NP, et al. Stabilization of remission in patients with opioid dependence with naltrexone implant: a pharmacogenetic approach. Zh Nevrol Psikhiatr Im S S Korsakova. 2015;115:14-23.

77. Kibitov AO, Krupitsky EM, Blokhina EA, Verbitskaya EV, Brodyansky VM, Alekseeva NP, et al. A pharmacogenetic analysis of dopaminergic and opioidergic genes in opioid addicts treated with the combination of naltrexone and guanfacine. $\mathrm{Zh}$ Nevrol Psikhiatr Im S S Korsakova. 2016;116:36-48.

78. Barbitoff YA, Bezdvornykh IV, Polev DE, Serebryakova EA, Glotov AS, Glotov OS, et al. Catching hidden variation: systematic correction of reference minor alleles in clinical variant calling. Genet Med. 2018;20:360-4.

79. Zhernakova DV, Kliver S, Cherkasov N, Tamazian G, Rotkevich M, Krasheninnikova K, et al. Analytical "bake-off" of whole genome sequencing quality for the Genome Russia project using a small cohort for autoimmune hepatitis. PLoS ONE. 2018;13(7): e0200423.

80. Leo D, Sukhanov I, Zoratto F, Illiano P, Caffino L, Sanna F, et al. Pronounced hyperactivity, cognitive dysfunctions, and BDNF dysregulation in dopamine transporter knock-out Rats. J Neurosci. 2018;38:1959-72.
81. Hou L, Heilbronner U, Degenhardt F, Adli M, Akiyama K, Akula $\mathrm{N}$, et al. Genetic variants associated with response to lithium treatment in bipolar disorder: a genome-wide association study. Lancet. 2016;387:1085-93.

82. Al Hadithy AFY, Ivanova SA, Pechlivanoglou P, Semke A, Fedorenko O, Kornetova E, et al. Tardive dyskinesia and DRD3, HTR $2 A$ and HTR2C gene polymorphisms in Russian psychiatric inpatients from Siberia. Progress Neuropsychopharmacol Biol Psychiatry. 2009;33:475-81.

83. Al Hadithy AF, Ivanova SA, Pechlivanoglou P, Wilffert B, Semke $\mathrm{A}$, Fedorenko $\mathrm{O}$, et al. Missense polymorphisms in three oxidative-stress enzymes (GSTP1, SOD2, and GPX1) and dyskinesias in Russian psychiatric inpatients from Siberia. Hum Psychopharmacol. 2010;25:84-91.

84. Ivanova SA, Loonen AJM, Pechlivanoglou P, Freidin MB, Al Hadithy AFY, Rudikov EV, et al. NMDA receptor genotypes associated with the vulnerability to develop dyskinesia. Translational. Psychiatry. 2012;2:e67.

85. Loonen AJ, Ivanova SA. New insights into the mechanism of drug-induced dyskinesia. CNS Spectr. 2013;18:15-20.

86. Ivanova SA, Filipenko ML, Vyalova NM, Voronina EN, Pozhidaev IV, Osmanova DZ, et al. CYP1A2 and CYP2D6 gene polymorphisms in Schizophrenic patients with neuroleptic druginduced side effects. Bull Exp Biol Med. 2016;160:687-90.

87. Ivanova SA, Geers LM, Al Hadithy AF, Pechlivanoglou P, Semke $\mathrm{AV}$, Vyalova NM, et al. Dehydroepiandrosterone sulphate as a putative protective factor against tardive dyskinesia. Prog Neuropsychopharmacol Biol Psychiatry. 2014;50:172-7.

88. Ivanova SA, Toshchakova VA, Filipenko ML, Fedorenko OY, Boyarko EG, Boyko AS, et al. Cytochrome P450 1A2 gene polymorphism may diminish tardive dyskinesia by increased inducibility. World J Biol Psychiatry. 2015;16:200-5.

89. Fedorenko OY, Loonen AJ, Lang F, Toshachakova VA, Boyarko EG, Semke AV et al. Association study indicates a protective role of phosphatidylinositol-4-phosphate-5-kinase against tardive dyskinesia. Int J Neuropsychopharmacol. 2014; 18: pii: pyu098.

90. Ivanova SA, Al Hadithy AF, Brazovskaya N, Semke A, Wilffert $\mathrm{B}$, Fedorenko O, et al. No involvement of the adenosine A2A receptor in tardive dyskinesia in Russian psychiatric inpatients from Siberia. Hum Psychopharmacol. 2012;27:334-7.

91. Ivanova SA, Loonen AJ, Bakker PR, Freidin MB, Ter Woerds NJ, Al Hadithy AF, et al. Likelihood of mechanistic roles for dopaminergic, serotonergic and glutamatergic receptors in tardive dyskinesia: A comparison of genetic variants in two independent patient populations. SAGE Open Med. 2016;4:2050312116643673.

92. Ivanova SA, Osmanova DZ, Freidin MB, Fedorenko OY, Boiko AS, Pozhidaev IV, et al. Identification of 5-hydroxytryptamine receptor gene polymorphisms modulating hyperprolactinaemia in antipsychotic drug-treated patients with schizophrenia. World J Biol Psychiatry. 2017;18:239-46.

93. Fedorenko OYu, Loonen AJM, Vyalova NM, Boiko AS, Pozhidaev IV, Osmanova DZ, et al. Hyperprolactinemia and CYP2D6, $D R D 2$ and HTR2C genes polymorphism in patients with schizophrenia. Physiol Pharmacol. 2017;21:25-33.

94. Ivanova SA, Osmanova DZ, Boiko AS, Pozhidaev IV, Freidin MB, Fedorenko OY, et al. Prolactin gene polymorphism (-1149G/ $\mathrm{T})$ is associated with hyperprolactinemia in patients with schizophrenia treated with antipsychotics. Schizophr Res. 2017; 182:110-4. 


\section{Author Information}

Olga Yu. Fedorenko ${ }^{1,2} \cdot$ Vera E. Golimbet ${ }^{3} \cdot$ Svetlana A. Ivanova $^{1,2} \cdot$ Anastasia Levchenko $^{4} \cdot$ Raul R. Gainetdinov $^{4}$. Arkady V. Semke ${ }^{1}$ German G. Simutkin ${ }^{1} \cdot$ Anna E. Gareeva ${ }^{5,6} \cdot$ Andrey S. Glotov $^{7} \cdot$ Anna Gryaznova $^{8}$. Ivan Y. lourov ${ }^{3}$ - Evgeny M. Krupitsky ${ }^{9}$ Igor N. Lebedev $\mathbb{1 0}^{10}$. Galina E. Mazo ${ }^{9}$. Vasily G. Kaleda ${ }^{3}$. Lilia I. Abramova ${ }^{3}$ - Igor V. Oleichik ${ }^{3}$ - Yulia A. Nasykhova ${ }^{7}$ - Regina F. Nasyrova ${ }^{9}$ Anton E. Nikolishin ${ }^{11}$. Evgeny D. Kasyanov $\mathbb{D}^{9} \cdot$ Grigory V. Rukavishnikov $\mathbb{D}^{9} \cdot$ Ilgiz F. Timerbulatov $^{6}$ • Vadim M. Brodyansky ${ }^{11}$. Svetlana G. Vorsanova ${ }^{12}$. Yury B. Yurov ${ }^{3}$. Tatyana V. Zhilyaeva $\mathbb{D}^{13}$. Anzhelika V. Sergeeva ${ }^{13}$. Elena A. Blokhina ${ }^{14}$. Edwin E. Zvartau ${ }^{14}{ }^{14} \cdot$ Anna S. Blagonravova $^{13} \cdot$ Lyubomir I. Aftanas $^{15} \cdot$ Nikolay A. Bokhan $^{1,16} \cdot$ Zurab I. Kekelidze $^{11}$. Tatyana V. Klimenko ${ }^{11}$. Irina P. Anokhina ${ }^{11}$. Elza K. Khusnutdinova ${ }^{5,6}$. Tatyana P. Klyushnik ${ }^{3}$.

Nikolay G. Neznanov ${ }^{9} \cdot$ Vadim A. Stepanov $^{10,16} \cdot$ Thomas G. Schulze $^{8} \cdot$ Aleksandr O. Kibitov $^{11}$

1 Mental Health Research Institute, Tomsk National Research Medical Center of Russian Academy of Sciences, Tomsk, Russian Federation

2 National Research Tomsk Polytechnic University, Tomsk, Russian Federation

3 Mental Health Research Center, Moscow, Russian Federation

4 Institute of Translational Biomedicine, Saint Petersburg State University, Saint Petersburg, Russian Federation

5 Institute of Biochemistry and Genetics, Ufa Federal Research Center, Russian Academy of Sciences, Ufa, Russian Federation

6 Federal State Educational Institution of Highest Education Bashkir State Medical University of Public Health Ministry of Russian Federation, Ufa, Russian Federation

7 Laboratory of Biobanking and Genomic Medicine of Institute of Translational Biomedicine, Saint Petersburg State University, Saint Petersburg, Russian Federation

8 Institute of Psychiatric Phenomics and Genomics (IPPG), University Hospital, LMU, Munich, Germany

9 V.M. Bekhterev National Medical Research Center for Psychiatry and Neurology, Saint Petersburg, Russian Federation

10 Research Institute of Medical Genetics, Tomsk National Research Medical Center of Russian Academy of Sciences, Tomsk, Russian Federation

11 Serbsky National Medical Research Center on Psychiatry and Addictions, Moscow, Russian Federation

12 Veltischev Research and Clinical Institute for Pediatrics, the Pirogov Russian National Research Medical University, Moscow, Russian Federation

13 Privolzhskiy Research Medical University, Nizhny Novgorod, Russian Federation

14 First Saint Petersburg Pavlov State Medical University, Saint Petersburg, Russian Federation

15 Federal State Scientific Budgetary Institution "Scientific Research Institute of Physiology and Basic Medicine,", Novosibirsk, Russian Federation

16 National Research Tomsk State University, Tomsk, Russian Federation 